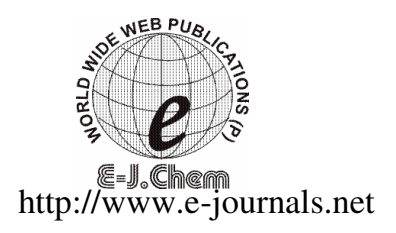

ISSN: 0973-4945; CODEN ECJHAO

E-Journal of Chemistry 2012, 9(1), 415-419

\title{
Acoustical Studies on the Ternary Mixture of 1, 4- Dioxane + Chloroform + Cyclohexane liquid Mixtures At 303.15, 308.15 and 313.15 K
}

\author{
V. VANATHI, S. MULLAINATHAN and S. NITHIYANANTHAM* \\ Department of Physics, AVC College of Engineering \\ Mayiladuthurai, Tamilnadu-609 306, India \\ *School of Physical Sciences and Nanotechnology \\ (Biophysics / Ultrasonics Division), SRM Univeristy \\ Kattankulathur, Tamilnadu-603 203, India \\ s_nithu59@rediffmail.com
}

Received 2 July 2011; Accepted 27 August 2011

\begin{abstract}
Ultrasonic velocity, density and viscosity of the ternary mixture of 1, 4- dioxane + chloroform + cyclohexane, were measured at 303.15, 308.15 and $313.15 \mathrm{~K}$. The thermodynamical parameters such as adiabatic compressibility $(\beta)$, intermolecular free length $\left(L_{f}\right)$, free volume $\left(V_{f}\right)$, internal pressure $\left(\pi_{i}\right)$, acoustic impedance $(Z)$, molar sound velocity $(R)$ and molar compressibility (W) have been obtained from the experimental data for all the mixtures, with a view to investigate the exact nature of molecular interaction. Adiabatic compressibility and intermolecular free length decrease with increase in concentration and temperature. The other parameters show almost increasing concentration of solutes. These parameters have been further used to interpret the molecular interaction part of the solute and solvent in the mixtures.
\end{abstract}

Keywords: Ultrasonic velocity, Organic liquids, Acoustical properties, Molecular interactions

\section{Introduction}

Ultrasonic velocity affects the physical properties of the medium and hence one can furnish information about the liquid and liquid mixtures. In recent years, ultrasonic velocity is gaining importance in understanding the nature of solute-solvent interactions ${ }^{1}$. Knowledge of thermodynamic and acoustical properties is of great significant in studying the physical behaviour and molecular interactions in a variety of liquid mixtures of pure ${ }^{2,3}$, liquid mixtures $^{4-6}$ and electrolytic solutions ${ }^{7-10}$. A survey of literature shows that scanty work has been done on binary mixtures phenol with some organic liquids ${ }^{4,5}$. The present work reports evaluation of some acoustical parameters of ternary mixtures of 1, 4- dioxane + chloroform + cyclohexane at $303.15,308.15$ and $313.15 \mathrm{~K}$. 
The adiabatic compressibility, intermolecuar free length, free volume, internaal pressure, acoustical impedance, Rao's constant and Wada's constant of mixtures at various temperatures haven been studied in the present paper. Such data are expected to highlight the role of solute and solvents in the solutions and its influence on temperature.

\section{Experimental}

The ultrasonic velocity in the liquid mixtures have been measured using an ultrasonic Interferometer (Mittal type -82, New Delhi, India) working at $2 \mathrm{MHz}$ frequency with accuracy $\pm 0.1 \mathrm{~ms}^{-1}$. The Interferometer is a fixed frequency variable path type. Ultrasound of constant frequency is generated at the bottom of the cylindrical sample cell using quartz crystal and is sent into the medium under study. The propagated waves after getting reflected at the reflector surface held at the top of the cell, again travels back through the same medium. These two waves form stationary wave pattern and hence nodes and antinodes are formed in the medium. A fine micrometer screw is provided in the set up that allows for finer movements of the reflector plate in the medium. Thus moving the reflector plate for a fixed number of antinode (or node) positions, the distance moved for a known number of waves can be known. Use of frequency with these data will yield the sound velocity in the medium. The density and viscosity are measured using a Pycnometer and an Ostwald's viscometer of accuracy of $\pm 0.1 \mathrm{kgm}^{-3}$ and $0.001 \mathrm{mNsm}^{-2}$ respectively. The samples are AnalaR grade of purity $99.5 \%$ and used directly without purification. The values of density, viscosity and velocity of pure samples are agreed well with the standard reference values. In all systems, the mole fraction of the second component, chloroform $\left(\mathrm{x}_{2}=0.2\right)$ was kept constant, while the mole fraction of the remaining $\left(\mathrm{x}_{1}\right.$ and $\left.\mathrm{x}_{3}\right)$ were varied from 0.1 to 0.8 as to have the different compositions ${ }^{11}$.

\section{Theoretical aspects}

Various acoustical parameters such as adiabatic compressibility, intermolecular free length, free volume, internal pressure, acoustical impedance, molar sound velocity, molar compressibility, classical absorption coefficient and relaxation time have been evaluated on the basis of experimental data on density, velocity and viscosity from the standard equations (1 - 7).

$\begin{array}{ll}\text { Adiabatic compressibility } & \beta=1 /\left(U^{2} / \rho\right) \\ \text { Free length } & L_{f}=K \beta^{1 / 2},\end{array}$

where $K$ is Jacobson constant $\left(6.0816 \times 10^{4}\right)$

Free volume

$$
V_{f}=\left(M_{e f f} U / \eta K\right)^{3 / 2}
$$

where $K$ - constant $\left(4.28 \times 10^{9}\right)$

Internal pressure $\quad \pi_{i}=b \mathrm{R} T(K \eta / U)^{1 / 2}\left(\rho^{2 / 3} / M^{7 / 6}\right)$

$b=$ atomic scaling factor $(=2), \mathrm{R}$ - Universal gas constant, $\mathrm{T}$ - temperature

Acoustical impedance

$$
\begin{aligned}
& Z=U \rho \\
& R=(M / \rho) U^{1 / 3} \\
& W=(M / \rho) \beta^{1 / 7}
\end{aligned}
$$$$
\text { and }
$$

Molar compressibility

\section{Results and Discussion}

From Table 1, the value of ultrasonic velocity is increasing trend with concentration of cyclohexane. The value of density also increasing trend with increasing molality of cyclohexane, increases the particles in the medium and so the values of sound velocity also increases. The increasing density values increases the frictional resistance between the 
constituents of the mixture, it tends to increase the coefficient of viscosity of the solutions. The observed increasing trend of sound velocity indicates association among the molecules and greater solute-solvent interaction, density and viscosity indicates that the existence of interaction between the constituents of the mixtures. The observed $(U),(\rho)$ and $(\eta)$ decreases with increasing temperature shows that the interaction are less at high temperatures. The higher values are observed in the order of $303.15>308.15>313.15 \mathrm{~K}$. The increase in thermal energy weakens the molecular forces and hence the decrease in velocity is expected.

Table 1. Measured values of ultrasonic velocity $(U)$, density $(\rho)$ and viscosity $(\eta)$ of 1- 4 Dioxane + chloroform + cyclohexane at $303.15,308.15$ and $313.15 \mathrm{~K}$

\begin{tabular}{|c|c|c|c|c|c|c|c|c|c|c|}
\hline \multirow{2}{*}{$\begin{array}{l}\stackrel{0}{Z} \\
\dot{s}\end{array}$} & \multirow{2}{*}{$\frac{\stackrel{3}{\frac{\pi}{0}}}{\sum^{\circ}} \Xi$} & \multicolumn{3}{|c|}{$\begin{array}{c}\mathrm{U} \\
\mathrm{ms}^{-1}\end{array}$} & \multicolumn{3}{|c|}{$\underset{\mathrm{kgm}^{-3}}{\rho}$} & \multicolumn{3}{|c|}{$\underset{\mathrm{Nsm}^{-2}}{\eta}$} \\
\hline & & 03.15 & 308.15 & 313.15 & 303.15 & 308.15 & 313.15 & 303.15 & 308.15 & 313.15 \\
\hline 1 & 0.01 & 1154 & 1146 & 1136 & 992.4 & 963.4 & 959.0 & 0.9427 & 0.9031 & \\
\hline 2 & .02 & 1 & 1140 & 1112 & 1001.4 & 997.8 & 996.6 & 0.9 & 0.9479 & 93 \\
\hline 3 & .03 & & 1120 & 1104 & 1030.4 & 1027.6 & 1025.6 & 0.9 & 0.9376 & 0.9102 \\
\hline 4 & .04 & & 11 & 10 & & 1068.8 & & 1.0 & 0.9619 & \\
\hline 5 & 0.05 & & 6 & 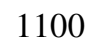 & 10 & 1086.4 & 10 & & 20 & \\
\hline 6 & 0.06 & & 8 & & & 114 & & & 87 & \\
\hline 1 & 0.07 & & 1160 & & & 1167.8 & 1166.2 & & 1.1240 & 1.1077 \\
\hline 8 & 0.08 & 1192 & 1144 & 1128 & 1177.6 & 1176.2 & 1174.8 & 1.2070 & 1.1762 & 1.1454 \\
\hline 9 & 0.09 & 1184 & 1136 & 1116 & 1192.6 & 1189.6 & 1186.4 & 1.2820 & 1.2490 & 1.2308 \\
\hline
\end{tabular}

From the Table 2 , the value of adiabatic compressibility $(\beta)$ the ease with which the medium can be compressed is higher in lower concentration. This shows the more available space, due to the density of the medium. Intermolecular free length depends upon adiabatic compressibility and shows a similar to that of compressibility's. The $\mathrm{L}_{\mathrm{f}}$ is found to be a predominant factor to determining the nature of ultrasonic velocity in liquid mixtures. The intermolecular free length $\left(\mathrm{L}_{\mathrm{f}}\right)$ is the mean distance between the surfaces of neighboring molecule, also reflects the same trend as that of $\beta$. This indicates significant interaction between solute and solvent molecules. With increase in temperature, since adiabatic compressibility increases, it clearly indicates temperature dependence of $\beta$. The value of intermolecular free length $\left(\mathrm{L}_{\mathrm{f}}\right)$ shows the decreasing trend in an increase of $(\mathrm{CYH})$ concentration in all solvent systems ${ }^{12,13}$. This is in agreement with the observations made by Syal et al. ${ }^{14}$ With increase in temperature, the magnitude of $\mathrm{L}_{\mathrm{f}}$ increases.

From the same Table 2, it is noticed that a concentration of $(\mathrm{CYH})$ increases, the free volume decrease whereas internal pressure increases. The internal pressure $\left(\pi_{\mathrm{i}}\right)$ is the resultant of force of attraction and force of repulsion per unit area between the components of the mixtures. The measured values are in same trend with that of the concentration of solutes, the average available volume between the molecules of mixture is referred as free volume $\left(\mathrm{V}_{\mathrm{f}}\right)$ reflects the reverse trend as that of internal pressure. However, with rise in temperature, increase in free volume and decrease in internal pressure are noticed in all systems. This suggests the close packing of the molecules inside the shield ${ }^{15,16}$.

From Table 3, it has been indicated that the values of molar sound velocity (R) and molar compressibility (W) observed are in increase in trend in all concentration and are independent of temperature, pressure and concentration for unassociated and weakly associated molecules. The values suggest the availability of more number of components in a given region thus leads to a tight packing of the medium and thereby increase the solute-solute interactions. In the present system, $\mathrm{R}$ and $\mathrm{W}$ are found to be independent of temperature but show a gradual increase as $(\mathrm{CYH})$ content is increased in the solvent mixture ${ }^{17,18}$. 
Table 2. Calculated values adiabatic compressibility $(\beta)$, intermolecular free length $\left(\mathrm{L}_{\mathrm{f}}\right)$, free volume $\left(\mathrm{V}_{\mathrm{f}}\right)$ and internal pressure $\left(\pi_{\mathrm{i}}\right)$ of 1,4-dioxane + chloroform + cyclo hexane at $303.15,308.15$ and $313.15 \mathrm{~K}$

\begin{tabular}{|c|c|c|c|c|c|c|c|c|c|c|c|c|c|}
\hline \multirow{2}{*}{$\begin{array}{l}Z_{2} \\
\dot{z}\end{array}$} & \multirow{2}{*}{$\begin{array}{l}\text { Molality, } \\
\mathrm{m}\end{array}$} & \multicolumn{3}{|c|}{$\begin{array}{c}\beta \times 10^{-10} \\
\mathrm{~N}^{-1} \mathrm{~m}^{2}\end{array}$} & \multicolumn{3}{|c|}{$\begin{array}{c}\mathrm{L}_{\mathrm{f}} \times 10^{-11} \\
\mathrm{~m}\end{array}$} & \multicolumn{3}{|c|}{$\begin{array}{l}\mathrm{V}_{\mathrm{f}} \times 10^{-3} \\
\mathrm{~m}^{3} \mathrm{~mol}^{-1}\end{array}$} & \multicolumn{3}{|c|}{$\begin{array}{c}\pi_{\mathrm{i}} \times 10^{5} \\
\mathrm{Nm}^{-2}\end{array}$} \\
\hline & & 303.15 & 308.15 & 313.15 & 303.15 & 308.15 & 313.15 & 303.15 & 308.15 & 313.15 & 303.15 & 308.15 & 313.15 \\
\hline 1 & 0 & 7.5666 & 7.9035 & 8.0 & 5. & 5.6113 & 5 & 2.6085 & 2.7040 & 2.7291 & 0.2248 & 0.2200 & 0.2219 \\
\hline 2 & 0.0 & 7.6302 & 7.7116 & 8.1 & 5. & 5.5428 & 5. & 2.5077 & 2.5738 & 2.6172 & 0.2300 & 0.2302 & 0.2318 \\
\hline 3 & 0.03 & 7.6273 & 7.7578 & 7.99 & 5.5 & 5.5594 & 5. & 2.4770 & 2.5675 & 2.6070 & 0.2185 & 0.2344 & 0.2361 \\
\hline 4 & 0.04 & 7.4969 & 7.5664 & 7.7977 & 5.4 & 5.4904 & 7 & 2.3994 & 2.4954 & 2.5321 & 0.2445 & 0.2434 & 0.2453 \\
\hline 5 & 0.05 & 7.2262 & 7.3906 & 7.6 & 5. & 5.4262 & & 2.3060 & 2.3443 & 2.3775 & 0.2513 & 0.2531 & 0.2551 \\
\hline 6 & 0.06 & 6.7783 & 6.8940 & 6.9999 & & 5.2407 & & 2.2773 & 2.2978 & 2.3 & 0.2606 & 0.2633 & 0.2646 \\
\hline 7 & 0 & 315 & 6.3637 & 6.4924 & 4.8 & 5.0351 & & 32 & 2.2563 & & 0.2640 & 0.2692 & 0.2723 \\
\hline 8 & & & 6.4963 & 6.2 & & 5.0873 & & & 2.1354 & & 0.2709 & 0.2773 & 0.2798 \\
\hline 9 & 0.09 & 5.9138 & 6.5139 & 6.2676 & 4.8539 & 5.0942 & 4.9970 & 2.0362 & 2.0052 & 1.9991 & 0.2811 & 0.2875 & 0.2921 \\
\hline
\end{tabular}

Table 3. Calculated values acoustical impedance (Z), molar sound velocity (R) and molar sound compressibility (W) of 1,4-dioxane + chloroform + cyclo hexane at $303.15,308.15$ and $313.15 \mathrm{~K}$

\begin{tabular}{|c|c|c|c|c|c|c|c|c|c|c|}
\hline \multirow{2}{*}{$\begin{array}{l}0 \\
z \\
i\end{array}$} & \multirow{2}{*}{$\begin{array}{c}\text { Molality, } \\
\mathrm{m}\end{array}$} & \multicolumn{3}{|c|}{$\mathrm{Z} \times 10^{6} \mathrm{kgm}^{-2} \mathrm{~s}^{-1}$} & \multicolumn{3}{|c|}{$\mathrm{R} \times 10^{-3} \mathrm{~m}^{10 / 3} \mathrm{~s}^{-1 / 3} \mathrm{~mol}^{-1}$} & \multicolumn{3}{|c|}{$\mathrm{W} \times 10^{3} \mathrm{~m}^{3} / \mathrm{mole},\left(\mathrm{N} / \mathrm{m}^{2}\right)^{1 / 7}$} \\
\hline & & 303.15 & 308.15 & 313.15 & 303.15 & 308.15 & 313.15 & 303.15 & 308.15 & 313.15 \\
\hline 1 & 0.01 & 1.1452 & 1.1040 & 1.0894 & 0.0963 & 0.0990 & 0.0992 & 0.1846 & 0.1890 & 0.1892 \\
\hline 2 & 0.02 & 1.1456 & 1.1374 & 1.1082 & 0.0956 & 0.0989 & 0.0952 & 0.1835 & 0.1839 & 0.1828 \\
\hline 3 & 0.03 & 1.1622 & 1.1509 & 1.1322 & 0.0929 & 0.0929 & 0.0927 & 0.1803 & 0.1792 & 0.1787 \\
\hline 4 & 0.04 & 1.1952 & 1.1885 & 1.1700 & 0.0894 & 0.0895 & 0.0892 & 0.1735 & 0.1736 & 0.1731 \\
\hline 5 & 0.05 & 1.2268 & 1.2124 & 1.1928 & 0.0888 & 0.0885 & 0.0883 & 0.1725 & 0.1721 & 0.1717 \\
\hline 6 & 0.06 & 1.2986 & 1.2859 & 1.2756 & 0.0854 & 0.0850 & 0.0849 & 0.1684 & 0.1664 & 0.1662 \\
\hline 7 & 0.07 & 1.4025 & 1.3546 & 1.3432 & 0.0850 & 0.0841 & 0.0841 & 0.1663 & 0.1650 & 0.1649 \\
\hline 8 & 0.08 & 1.4036 & 1.3455 & 1.3251 & 0.0846 & 0.08355 & 0.0832 & 0.1656 & 0.1640 & 0.1630 \\
\hline 9 & 0.09 & 1.4120 & 1.3513 & 1.3240 & 0.0837 & 0.08276 & 0.0825 & 0.1628 & 0.1618 & 0.1614 \\
\hline
\end{tabular}


From the Table 3, the acoustical impedance $\mathrm{Z}$ is the product of ultrasonic velocity and the density of the medium, in general increase with increase in molality of toluene. The higher values are observed in $303.15 \mathrm{~K}$ whereas lower values at $313.15 \mathrm{~K}$. An increase in trend of acoustical impedance hints the closeness of solute particle and hence enhancing the existing interactions. The observed increase in $\mathrm{Z}$ with composition of the mixture is an evidence for the presence of interaction between the components of the liquid mixtures under study. Similar conclusion was arrived by Hasun ${ }^{19}$, the same trend as that of $\mathrm{Z}$ by Suryanarayana ${ }^{20}$ and Raveendranath and Ramamurthy ${ }^{21}$. The same trend was observed in our earlier works ${ }^{22-25}$.

\section{Conclusion}

From the Ultrasonic measurements we can find a general conclusion about strong intermolecular interaction between the components in the mixtures, measured and calculated acoustical parameters, solute-solvent and solute-solute interactions are predicted, but solutesolvent interactions are higher than solute-solute interaction. The order of temperatures in $313.15>308.15>303.15 \mathrm{~K}$.

\section{References}

1. Kaulgud M V and Patil K J, Indian J Pure Appl Phys., 1975, 13, 322.

2. $\quad$ Varma R P and Surendra Kumar, Indian J Pure Appl Phys., 2000, 38(2), 96.

3. Yadav S S, Singh Y.P and Rajkumar, J Indian Coun Chem, 1999, 16, 20.

4. Sheshagiri K and Reddy KC, Acustica, 1973, 29, 59.

5. Ali A, Tiwari K, Nain A K and Chakravartty V, Indian J phys., 2000, 74B(5), 351.

6. Upadhyay S K, Indian J Chem., 2000, 39, 537.

7. Gnananba S and Rao B R, Indian J pure Appl Phys., 1969, 7, 468,

8. McDowali J M and Vincent C A, J Chem Soc Faraday Trans., 1974, 70, 1862.

9. Dack M R J, Bird K J and Parker A, Aust J Chem., 1975, 28, 955.

10. Owen B B and Kronick K L, J Phy Chem, 1961, 65, 84,

11. Vogel AI, Quantitative Organic Chemistry., (ELBS), 1959.

12. Nithiyanantham S and Palaniappan L, Acta Cinica Indica, 2005, 31, 533.

13. Nithiyanantham S and Palaniappan L, Acta Cinica Indica, 2006, 22, 392.

14. Syal. V K, Gautam R and Chauhan S, Ind. J Pure Appl Phys., 1998, 36, 108.

15. Mishra A P and Gautam S K, Ind J Chem., 2002, 41A, 1845.

16. Kalyanasundaram S, Natarajan B, Manuel Stephen A, Gopalan A, Acustica, 1997, 83, 74.

17. Nithya R, Nithiyanantham S, Mullainathan S and Rajasekaran.M, E-J Chem., 2009, 6(1), 138-140.

18. Nithiyanantham.M and Mullaiathan.S, E-J Chem., 2010, 7(2), 353-355.

19. Hassun S.K, Eur Polym J., 1988, 24, 795.

20. Suryanarayana CV, Ind J Chem., 1972, 10, 713.

21. Raveenthranatha K.R and Ramamoorthy L, Proc Int Cong Ultrason E, 1990, 35.

22. Nithiyanantha S and Palaniappan L, Euro Phy J Appl Phys., 2011, 53(3), 31101.

23. Nithiyanantham S and Palaniappan L, Fron Chem Chi., 2011, 6(2), 147.

24. Nithiyanantham.S and Palaniappan L, Rus J Phy Chem A, 2011, 85(12), 2126.

25. Vanathi V, Mullainathan S and Nithiyanantham S, Int J Cur Res Rev., 2011, 3(2), 164. 


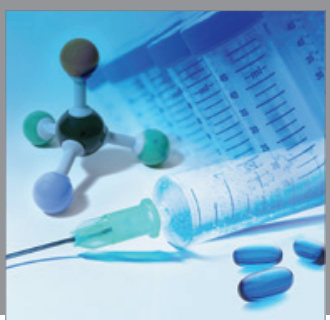

International Journal of

Medicinal Chemistry

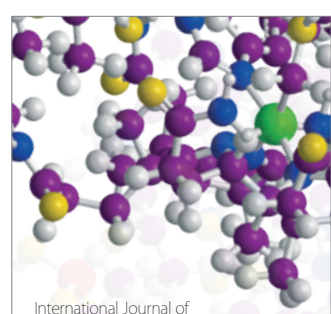

Carbohydrate Chemistry

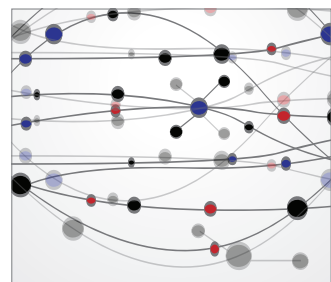

The Scientific World Journal
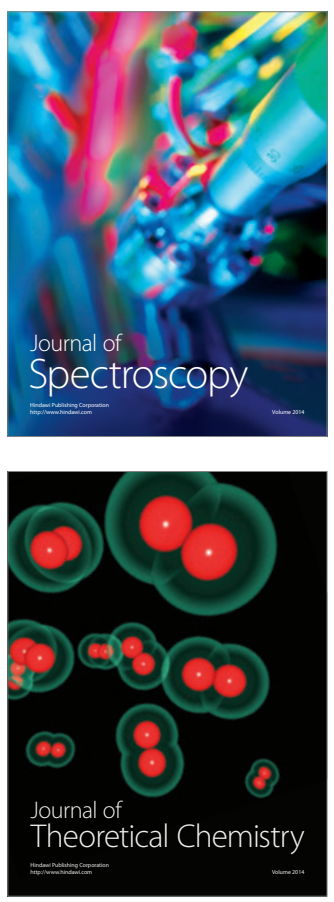
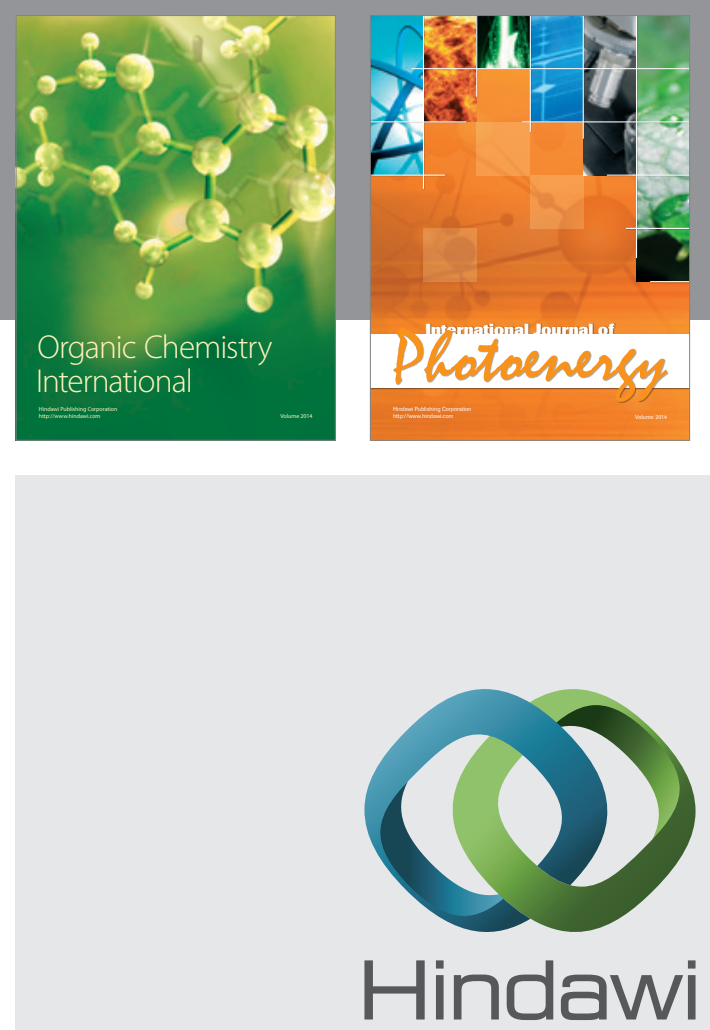

Submit your manuscripts at

http://www.hindawi.com
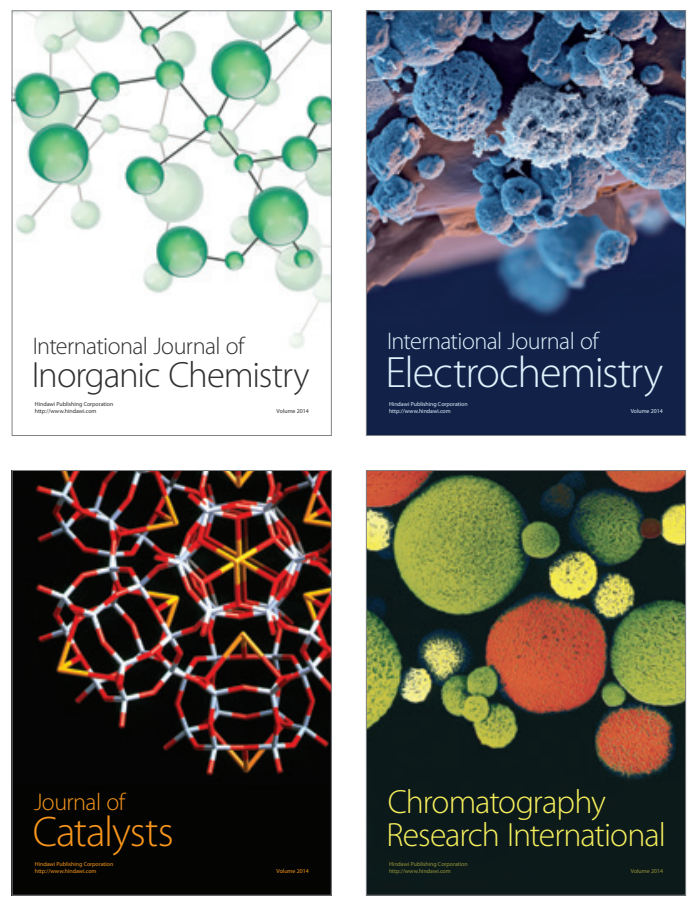
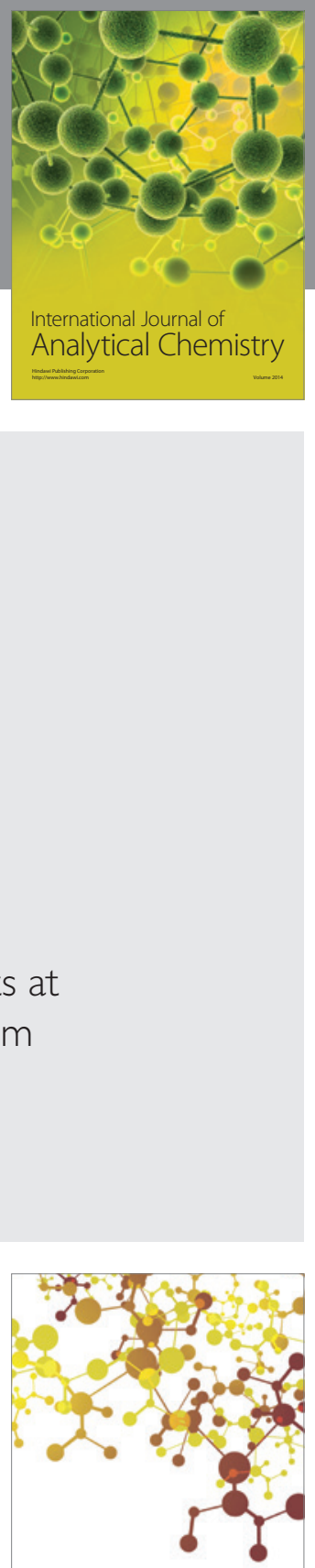

Journal of

Applied Chemistry
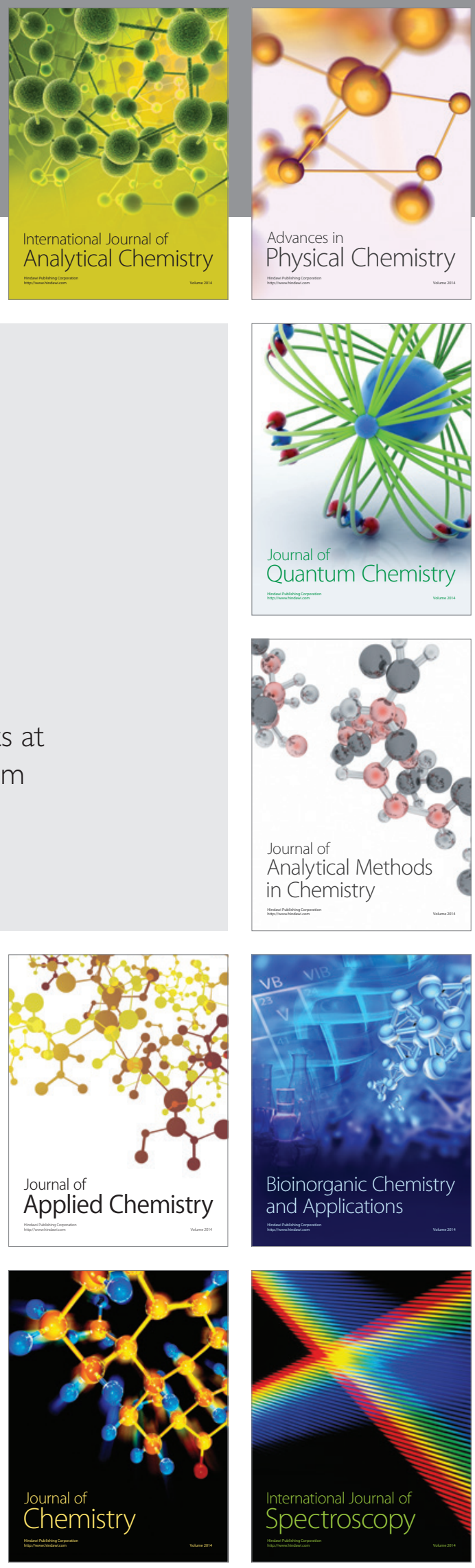